\title{
Synthesis of Co-Cr-Mo Fluorapatite Nano-Composite Coatings by Pulsed Laser Deposition for Dental Applications
}

\author{
Osama Khfagi ${ }^{1,2,3,4}$, Ntevheleni Thovhogi ${ }^{2,3}$, Dhiro Gihwala1,2,3, Malik Maaza ${ }^{2,3}$, Johan André Mars ${ }^{1}$ \\ ${ }^{1}$ Cape Peninsula University of Technology CPUT, Bellville, South Africa \\ ${ }^{2}$ UNESCO-UNISA African Chair in Nanosciences/Nanotechnology, College of Graduate Studies, University of South Africa, \\ Pretoria, South Africa \\ ${ }^{3}$ Nanosciences African Network (NANOAFNET), Materials Research Department, iThemba LABS-National Research Foundation \\ (NRF), Somerset West, South Africa \\ ${ }^{4}$ Higher Institute for Medical Professions, Ajdabiya, Libya \\ Email: awscar2003@gmail.com
}

How to cite this paper: Khfagi, O., Thovhogi, N., Gihwala, D., Maaza, M. and Mars, J.A. (2017) Synthesis of Co-Cr-Mo Fluorapatite Nano-Composite Coatings by Pulsed Laser Deposition for Dental Applications. Materials Sciences and Applications, 8, 135152.

https://doi.org/10.4236/msa.2017.82009

Received: August 26, 2016

Accepted: February 3, 2017

Published: February 6, 2017

Copyright $\odot 2017$ by authors and Scientific Research Publishing Inc. This work is licensed under the Creative Commons Attribution International License (CC BY 4.0).

http://creativecommons.org/licenses/by/4.0/

\begin{abstract}
Aim: The study was to fabricate FA nanopowder/Co-Cr-Mo dental alloy nanocomposite using pulsed laser deposition (PLD), and to evaluate bioactivity properties on simulated body fluid. Methods: In this work, the FA nanopowder was prepared by mixing calcium hydroxide $\left(\mathrm{Ca}(\mathrm{OH})_{2}\right)$, phosphorouspent oxide $\left(\mathrm{P}_{2} \mathrm{O}_{5}\right)$ and calcium fluoride $\left(\mathrm{CaF}_{2}\right)$ in a planetary high energy ball mill using zirconium vial. Fluorapatite (FA) nanopowder was processed in the form of pellet for pulsed laser deposition process. The Co-Cr-Mo alloy was coated with FA nanopowder which was approximately $35-65 \mathrm{~nm}$ at various laser energy, pressure and time. The X-ray diffraction (XRD) was used to analyze phase, crystallinity and size distribution of $\mathrm{Co}-\mathrm{Cr}-\mathrm{Mo} / \mathrm{FA}$ nanocomposite. The surface analysis was by scanning electron microscopy (SEM), Atomic Force microscopy (AFM) and Energy dispersive spectroscopy (EDS). Results: From the results obtained, It was shown that FA nanopowder deposited on $\mathrm{Co}-\mathrm{Cr}$ Mo alloy was stable during 14 days of incubation on simulated body fluid. It was also observed that the FA nanopowder coated on the surface of the alloy was still intact after the deposition process, which indicated the bioactivity and biocompatibility of the material. Conclusions: The fabrication of FA nanocomposite based dental alloys (Co-Cr-Mo) using PLD was done successfully. This was confirmed by various characterization techniques, which included XRD, AFM, SEM and EDS.
\end{abstract}

\section{Keywords}

Biocompatibility, Cobalt-Chromium-Molybdenum Alloys, Dental Alloys, 
Fluorapatite, Pulsed Laser Deposition (PLD), Simulated Body Fluid (SBF)

\section{Introduction}

Dental alloys and metals play an important role in dentistry. Although the latest trend is towards the "metal free" dentistry, the metals remain the only clinically proven material for long term dental applications. Dental alloy is a mixture of metallic elements or compounds with other metalloic elements in varying proportions for use in restorative or prosthetic dentistry. The alloys are widely used in dentistry for many years. However, it is of paramount importance to understand the biocompatibility of alloys for their long term success in rendering successful dental treatment [1] [2] [3].

Metallic materials play an essential role in assisting with the repair or replacement of diseased or damage bone tissue. Metals are more suitable for load bearing applications compared with ceramics or polymeric materials because they combine high mechanical strength and fracture toughness [4]. However, the main limitation of these metallic materials is the release of the toxic metallic ions that can lead to various adverse tissue reactions and/or hypersensitivity reactions [5]. Corrosion resistance is also a very important property for dental alloys, in addition to other properties such as strength, ductility and casting accuracy. Corrosion of dental alloys in the oral environment not only results in the deterioration of restoration, but also involves release of ions that is considered unclear to their biocompatibility [6].

Metals had been used in dentistry for many years [7]. The first metallic material used in stomatology was gold in foil form, used as loss and tooth decay fillers. Unfortunately this material could not be applied to customized crowns and bridges because of their low strength [8] [9] [10]. Cobalt-chromium-molybdenum (Co-Cr-Mo) alloys have been widely used as removable partial dentures metal frames and porcelain-fused-to-metal crowns [11] [12] [13]. The reason for this is that these materials are strong and resistant to corrosion. These alloys have also been used in other application such as in orthopedics, for bone fixation devices, total hip and knee replacements in both the cast and wrought forms. However, despite these properties, the fabrication processes, such as casting, cutting and plastic works are usually difficult due to their high melting point (1623 - 1723 $\mathrm{K})$, hardness and limited ductility [14] [15]. Therefore, this contribution reports on the fabrication of FA/Co-Cr-Mo nanocomposite using Pulsed Laser Deposition method and a possible application in dentistry.

\section{Materials and Methods}

The Co-Cr-Mo dental alloys were purchased from American Elements (USA), and were provided as a small disk (ASTM F75). The Co-Cr-Mo alloy chemical composition is shown in Table 1 as provided by the manufactures. The Co-Cr-Mo dental alloys were purchased in the form of a cylinder of $2 \mathrm{~cm}$ diameter and a 2 $\mathrm{cm}$ height. 
Table 1. Chemical composition (wt\%) of Co-Cr-Mo alloys.

\begin{tabular}{cc}
\hline Element & wt\% \\
\hline Co & 64 \\
Cr & 28 \\
Mo & 5 \\
C & Max 0.35 \\
Mn & Max 0.35 \\
Si & Max 0.35 \\
\hline
\end{tabular}

\subsection{Samples Preparation}

The dental alloys (Co-Cr-Mo) shown in Figure 1 were cut using Colchester $5 \times$ 20 Chipmaster Machine (Beckman, Scotland) into $0.1 \mathrm{~cm}$ height, sized tablet which was then cut into four parts to form $1 \mathrm{~cm}$ in diameter each. The original and reduced sizes of dental alloys are indicated in Figure 1.

\subsection{Preparation of Fluorapatite Nanopowder}

The preparation of fluorapatite nanopowder was performed as described in the literature [6]. The fluorapatite nanopowder was prepared by mixing calcium hydroxide $\left(\mathrm{Ca}(\mathrm{OH})_{2}\right)$, phosphorous-pent oxide $\left(\mathrm{P}_{2} \mathrm{O}_{5}\right)$ and calcium fluoride $\left(\mathrm{CaF}_{2}\right)$ in a laboratory scale ball-milling machine (Beckman, Scotland), using zirconium vial and zirconium balls with ball-to powder weight ratio of $35: 1$, rotational speed of $300 \mathrm{rpm}$, and a time of $6 \mathrm{~h}$. The fluorapatite nanopowder particles were obtained at approximately $35-65 \mathrm{~nm}$.

\subsection{Preparation of Fluorapatite Nanopowder Pellets}

The pellets of diameter $20 \mathrm{~mm}$ and a $3 \mathrm{~mm}$ height were prepared using the lab pellet presses, (Beckman, Scotland) (Figure 2). This was done under the pressure of 12 tons for a period of 30 minutes.

\subsection{Preparation of FA Nanopowder on Co-Cr-Mo Alloy by PLD}

The dental alloys were cut into four quarts section and were cleaned by acetone and distilled water prior to PLD analysis. The target-to-substrate distance was maintained at $3.8 \mathrm{~cm}$. Various samples were prepared at different deposition time laser energy and pressure. All of the depositions were performed at room temperature following procedure indicated in Table 2.

\subsection{Preparation of Simulated Body Fluid (SBF)}

The simulated body fluid was prepared in the laboratory with the ionic concentration nearly similar to human blood plasma. The fluid was prepared according to a procedure developed by Kokubo, as reported in the literature [9], and as summarized in Table 3. The appropriate quantities of reagents including $\mathrm{NaCl}$, $\mathrm{NaHCO}_{3}, \mathrm{KCl}, \mathrm{K}_{2} \mathrm{HPO}_{4} \cdot 3 \mathrm{H}_{2} \mathrm{O}, \mathrm{MgCl}_{2} \cdot 6 \mathrm{H}_{2} \mathrm{O}, \mathrm{CaCl}_{2}, \mathrm{Na}_{2} \mathrm{SO}_{4}$, were weighed, and dissolved in $1 \mathrm{~L}$ of double distilled water. This was to have an ionic concentration 


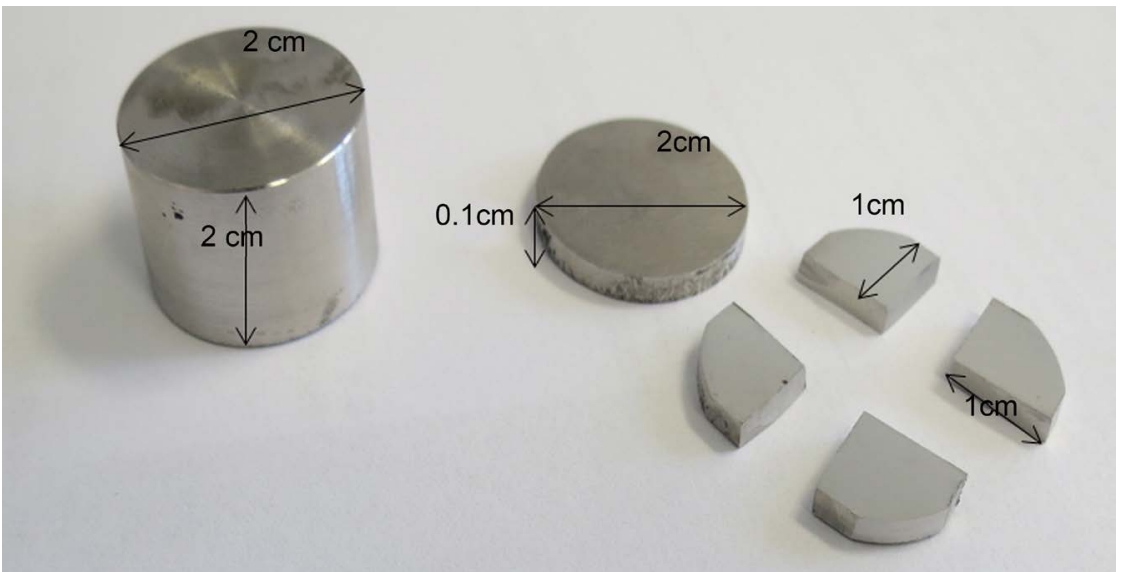

Figure 1. Illustration of Co-Cr-Mo alloy before and after the cutting.

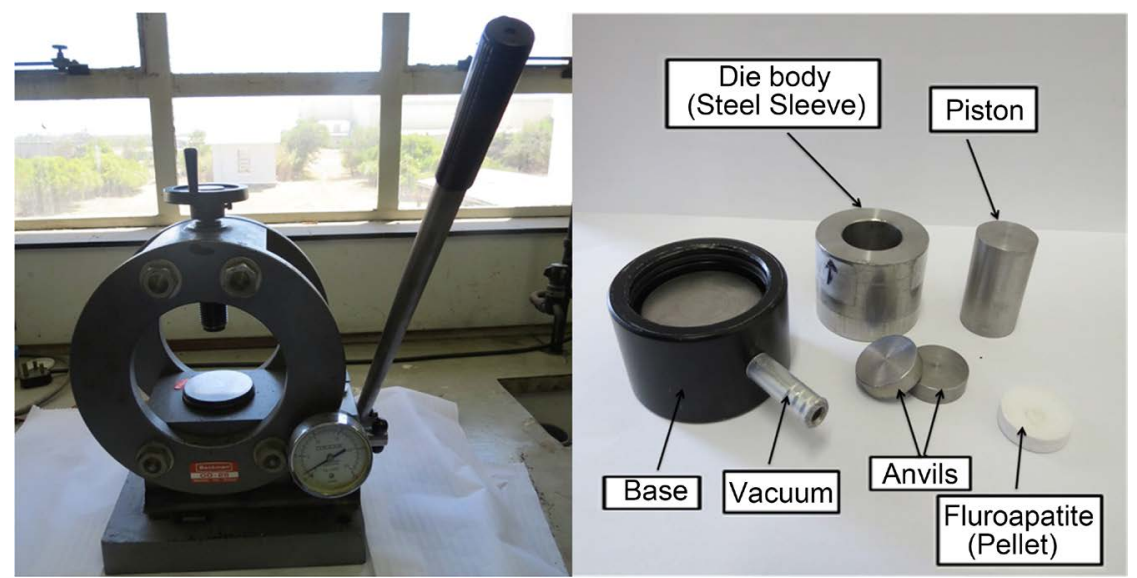

Figure 2. Lab Pellet Presses (Beckman) 00-25, Glenrothes Fife Scotland (ot the left), Evacuable pellet die set used to form $20 \mathrm{~mm}$ sample disks (to the right).

Table 2. Illustration of different laser energy, pressure and time used during Laser deposition of each sample.

\begin{tabular}{cccc}
\hline Sample & Laser energy $(\mathrm{mJ})$ & Presser & Deposition time \\
\hline a & $130 \mathrm{~mJ}$ & $7 \times 10^{-9} \mathrm{MPa}$ & $5 \mathrm{~min}$ \\
$\mathrm{~b}$ & $130 \mathrm{~mJ}$ & $7 \times 10^{-9} \mathrm{MPa}$ & $10 \mathrm{~min}$ \\
$\mathrm{c}$ & $130 \mathrm{~mJ}$ & $7 \times 10^{-9} \mathrm{MPa}$ & $20 \mathrm{~min}$ \\
$\mathrm{~d}$ & $170 \mathrm{~mJ}$ & $7 \times 10^{-9} \mathrm{MPa}$ & $10 \mathrm{~min}$ \\
e & $170 \mathrm{~mJ}$ & $7 \times 10^{-9} \mathrm{MPa}$ & $15 \mathrm{~min}$ \\
\hline
\end{tabular}

of various inorganic ions similar to those of the human blood plasma. The reagents were added, one after another, ensuring complete dissolution. $\mathrm{HCl}$ was added to maintain the $\mathrm{pH}$ of the solution at 7.4. The temperature of the solution was maintained at $37^{\circ} \mathrm{C}$.

The SBF was then prepared according to Table 4, following the procedure described in the literature [12]. Reagents were added, one after another, ensuring complete dissolution. $\mathrm{HCl}$ was added to maintain the $\mathrm{pH}$ of the solution at 7.4. The temperature of the solution was maintained at $37^{\circ} \mathrm{C}$. 
Table 3. Ion concentrations $\left(\mathrm{mmol} / \mathrm{dm}^{3}\right)$ of SBF and Human Blood Plasma. The reagents were prepared as indicated in the literature [9].

\begin{tabular}{ccccccc}
\hline & Human Plasma & Ringer & EBSS & HBSS & Kokubo-SBF & Tas-SBF \\
\hline $\mathrm{Na}^{+}$ & 142 & 130 & 143.6 & 138 & 142 & 142 \\
$\mathrm{~K}^{+}$ & 5 & 4 & 5.37 & 6.14 & 5 & 5 \\
$\mathrm{Ca}^{2+}$ & 2.5 & 1.4 & 1.8 & 1.26 & 2.5 & 2.5 \\
$\mathrm{Mg}^{2+}$ & 1.5 & - & 0.81 & 0.81 & 1.5 & 1.5 \\
$\mathrm{Cl}^{-}$ & 103 & 109 & 125.3 & 144.8 & 147.8 & 125 \\
$\mathrm{HCO}^{3-}$ & 27 & - & 26.2 & 4.2 & 4.2 & 27 \\
$\mathrm{HPO}_{4}^{2-}$ & 1 & - & 1 & 0.78 & 1 & 1 \\
$\mathrm{SO}_{4}^{2-}$ & 0.5 & - & 0.81 & 0.81 & 0.5 & 0.5 \\
$\mathrm{Ca}^{2-}$ & 2.5 & - & 1.8 & 1.62 & 2.5 & 2.5 \\
$\mathrm{Buffer}^{2-}$ & - & - & - & - & Tris & Tris \\
$\mathrm{pH}$ & 7.4 & 6.5 & $7.2-7.6$ & $6.7-6.9$ & 7.4 & 7.4 \\
\hline
\end{tabular}

Table 4. Reagents used for preparing SBF. The reagents were prepared as indicated in the literature [12].

\begin{tabular}{ccc}
\hline Order & Reagent & Amount $(\mathrm{g} / \mathrm{l})$ \\
\hline 1 & $\mathrm{NaCl}$ & $7.996 \mathrm{~g}$ \\
2 & $\mathrm{NaHCO}_{3}$ & $0.350 \mathrm{~g}$ \\
3 & $\mathrm{KCl}$ & $0.224 \mathrm{~g}$ \\
4 & $\mathrm{~K}_{2} \mathrm{HPO}_{4} \cdot 3 \mathrm{H}_{2} \mathrm{O}$ & $0.228 \mathrm{~g}$ \\
5 & $\mathrm{MgCl}_{2} \cdot 6 \mathrm{H}_{2} \mathrm{O}$ & $0.305 \mathrm{~g}$ \\
6 & $1 \mathrm{M}-\mathrm{HCl}^{-}$ & $40 \mathrm{ml}$ \\
7 & $\mathrm{CaCl}_{2}$ & $0.278 \mathrm{~g}$ \\
8 & $\mathrm{Na}_{2} \mathrm{SO}_{4}$ & $0.071 \mathrm{~g}$ \\
9 & $\left(\mathrm{CH}_{2} \mathrm{OH}\right)_{3} \mathrm{CNH}_{2}$ & $6.057 \mathrm{~g}$ \\
\hline
\end{tabular}

\section{Characterization of Materials}

\subsection{Pulsed Laser Ablation}

Pulsed laser deposition (PLD) is a growth technique in which the photon, laser energy is characterized by pulse duration and laser frequency, interacting with a bulk material [2]. As a result, material is removed from the bulk depending on the absorption properties of the target materials.

\subsection{Scanning Electron Microscope (SEM)}

Scanning electron microscopy (SEM) is a type of electron microscope, which is used for various purposes: Topographic studies, Microstructure analysis, Phase morphology, Chemical composition, Elemental mapping and Elemental analysis if equipped with appropriate detector (energy/wavelength dispersive X-rays). 


\subsection{Energy-Dispersive Analysis of X-Rays Spectroscopy (EDAX)}

The EDAX system is mostly connected to the electron microscopes such as SEM, FE-SEM and HR-TEM. EDAX spectra of the corresponding elements of the sample are obtained by measuring the energy of X-rays emitted from the sample during e-beam bombardment. X-rays are produced as a result of ionization of an atom when the incident electrons have removed an inner shell electron.

\section{Results and Discussion}

\subsection{Instrumental Analysis of the Specimens before Immersion into Simulated Body Fluid (SBF)}

\subsubsection{Microstructural Topology Analysis of Samples by SEM}

The SEM micrographs showing surface morphology of fluorapatite nanopowder/Co-Cr-Mo alloy nanocomposites before exposed to the simulated body fluid are presented in Figures 2-7. The particles of different sizes and their dispersity were observed.

The laser energy was $130 \mathrm{~mJ}$ and the pressure was maintained at $7 \times 10^{-9} \mathrm{MPa}$. The exposure time was five minutes. The micrograph was obtained by irradiating the specimen with a beam of electrons of energy $5 \mathrm{keV}$. The irradiation live-time was 120 seconds and the working distance was kept maintained at $4.2 \pm$ $0.2 \mathrm{~mm}$.

The laser energy was $130 \mathrm{~mJ}$ and the pressure was maintained at $7 \times 10^{-9} \mathrm{MPa}$. The exposure time was 10 minutes. The micrograph was obtained by irradiating the specimen with a beam of electrons of energy $5 \mathrm{keV}$. The irradiation live-time was 120 seconds and the working distance was kept maintained at $4.2 \pm 0.2 \mathrm{~mm}$.

The laser energy was $130 \mathrm{~mJ}$ and the pressure was maintained at $7 \times 10^{-9} \mathrm{MPa}$. The exposure time was 20 minutes. The micrograph was obtained by irradiating

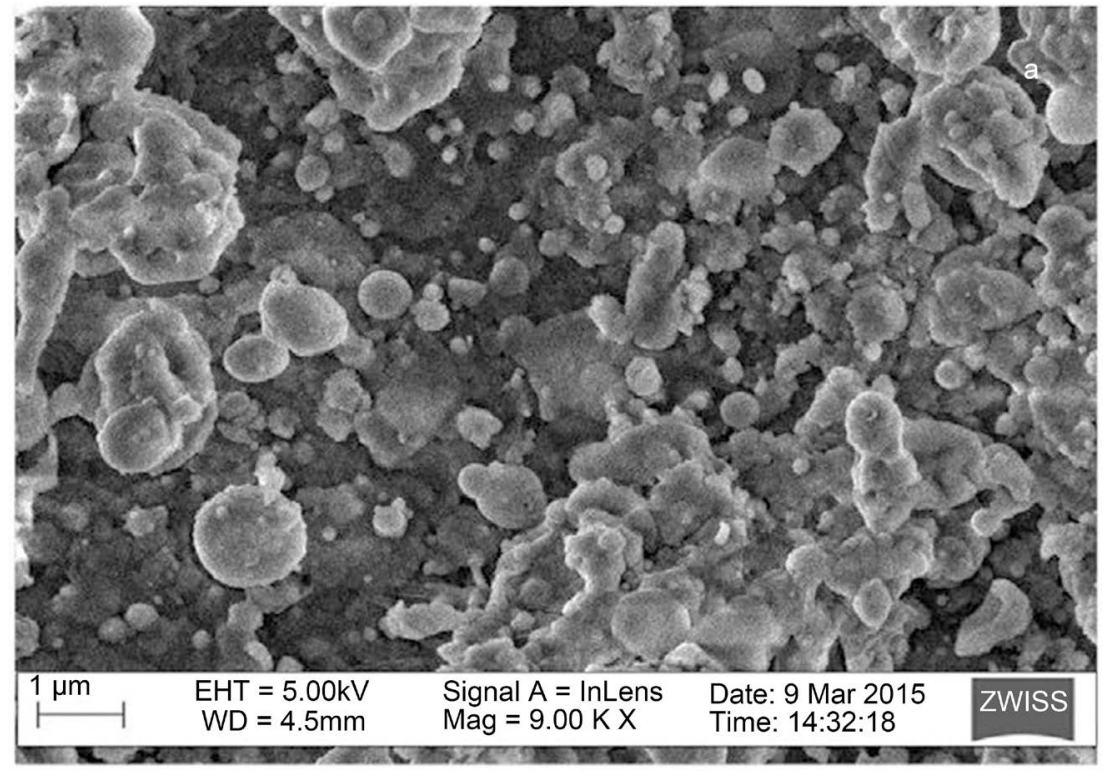

Figure 3. Electron micrograph of the microstructural topology of fluorapatite nanopowder-Co-Cr-Mo alloy coatings by Pulsed Laser Deposition. 


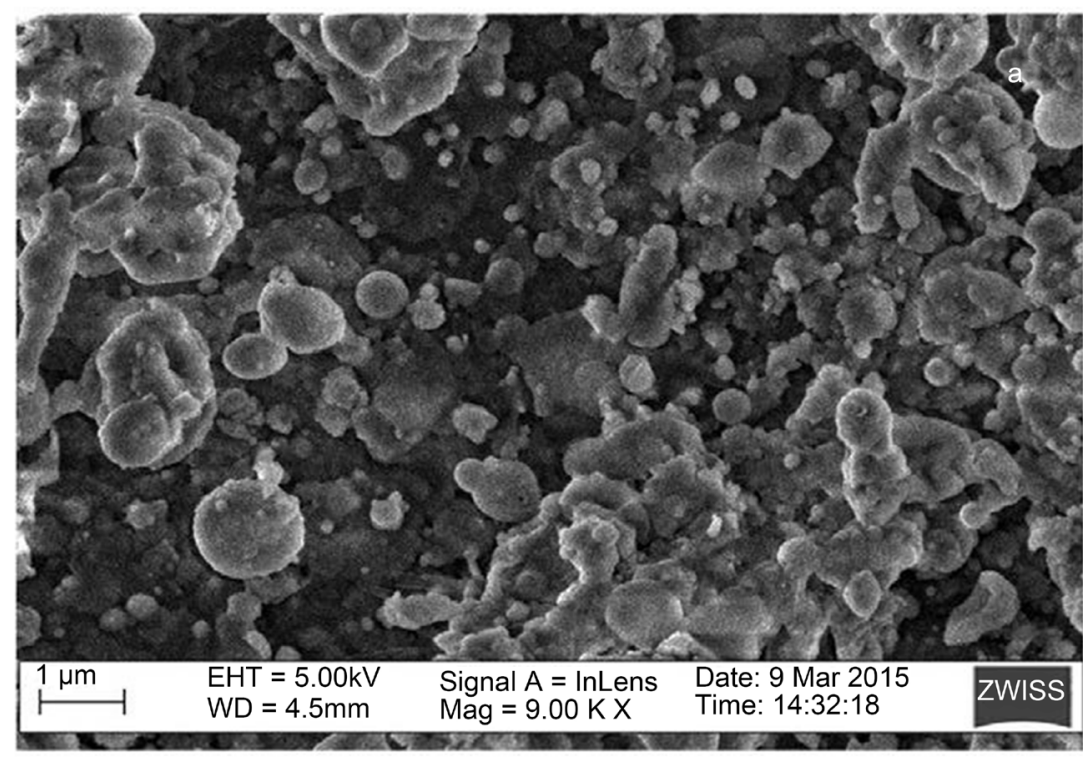

Figure 4. Electron micrograph of the microstructural topology of fluorapatite nanopowder-Co-Cr-Mo alloy coatings by Pulsed Laser Deposition.

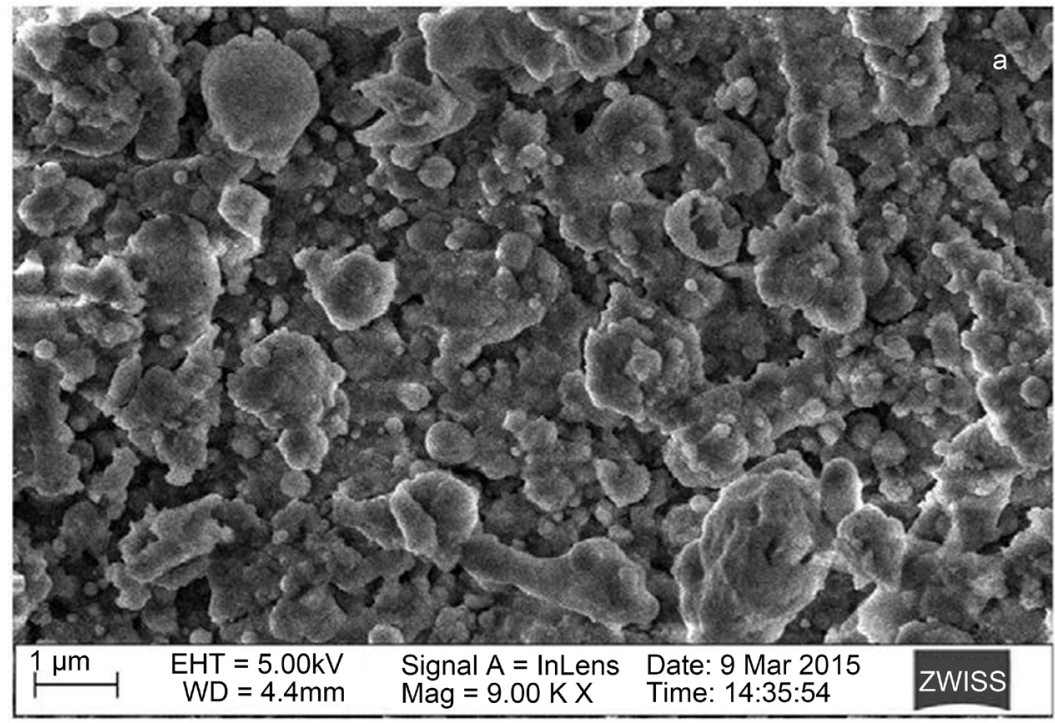

Figure 5. Electron micrograph of the microstructural topology of fluorapatite nanopowder-Co-Cr-Mo alloy coatings by Pulsed Laser Deposition.

the specimen with a beam of electrons of energy $5 \mathrm{keV}$. The irradiation live-time was 120 seconds and the working distance was kept maintained at $4.2 \pm 0.2 \mathrm{~mm}$.

The laser energy was $170 \mathrm{~mJ}$ and the pressure was maintained at $7 \times 10^{-9} \mathrm{MPa}$. The exposure time was 10 minutes. The micrograph was obtained by irradiating the specimen with a beam of electrons of energy $5 \mathrm{keV}$. The irradiation live-time was 120 seconds and the working distance was kept maintained at $4.2 \pm 0.2 \mathrm{~mm}$.

The laser energy was $170 \mathrm{~mJ}$ and the pressure was maintained at $7 \times 10^{-9} \mathrm{MPa}$. The exposure time was 15 minutes. The micrograph was obtained by irradiating the specimen with a beam of electrons of energy $5 \mathrm{keV}$. The irradiation live-time was 120 seconds and the working distance was kept maintained at $4.2 \pm 0.2 \mathrm{~mm}$. 


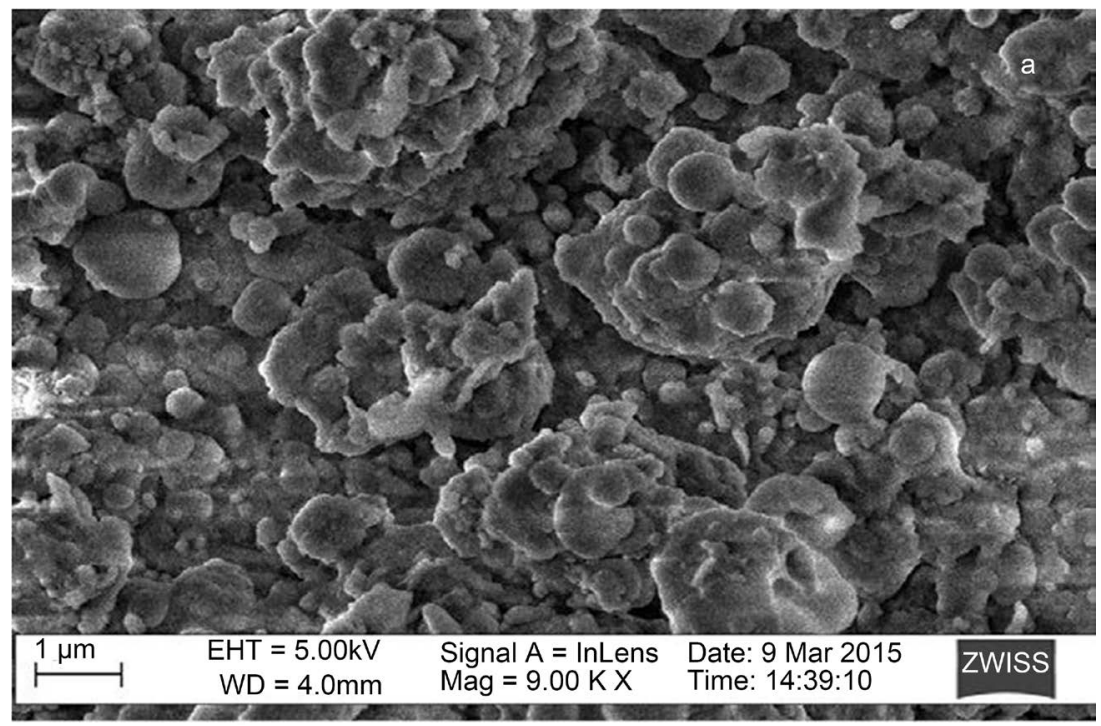

Figure 6. Electron micrograph of the microstructural topology of fluorapatite nanopowder-Co-Cr-Mo alloy coatings by Pulsed Laser Deposition.

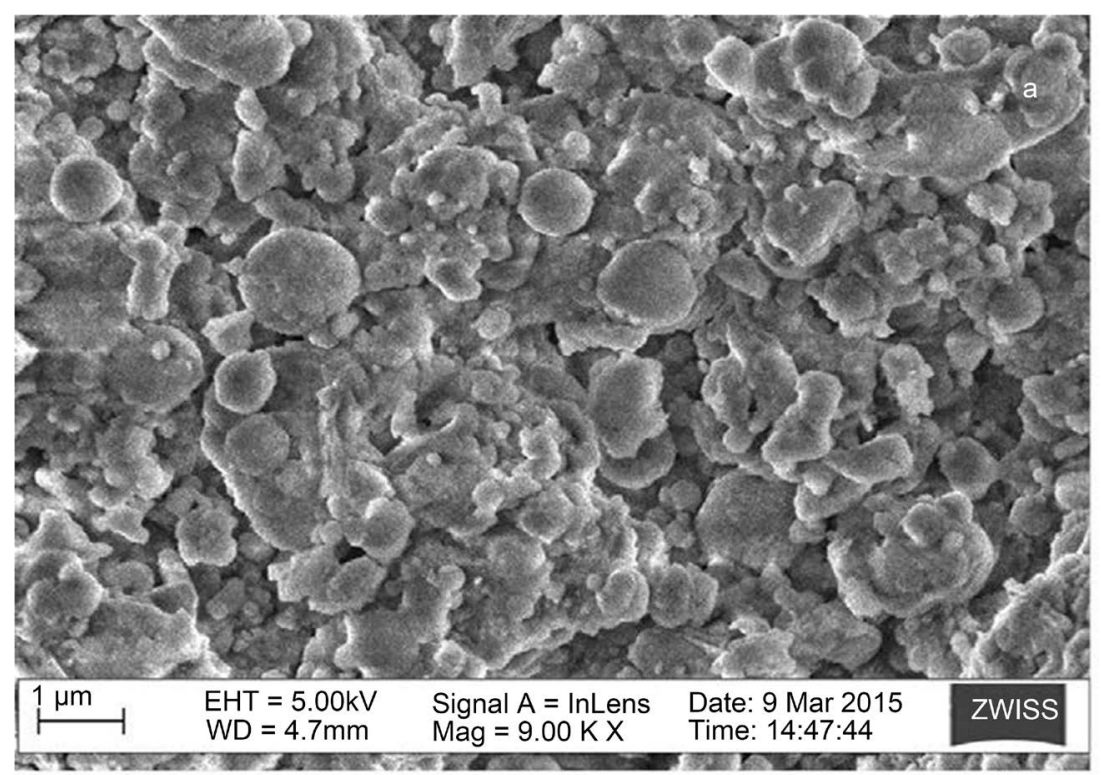

Figure 7. Electron micrograph of the microstructural topology of fluorapatite nanopowder-Co-Cr-Mo alloy coatings by Pulsed Laser Deposition.

\subsubsection{Energy Dispersive Analysis of X-Rays (EDAX) Analysis}

Figures 8-12 indicate the EDAX analysis of the deposited fluorapatite on the Co-Cr-Mo alloy at energy $130 \mathrm{~mJ}$. It is noticeable that the density of the deposition increased significantly and therefore correlated to the exposure time of FA deposited on the Co-Cr-Mo alloy. In the instance where the energy was $170 \mathrm{~mJ}$, a significant in the density was also observed.

The laser energy was $130 \mathrm{~mJ}$ and $170 \mathrm{~mJ}$ and the pressure was maintained at 7 $\times 10^{-9} \mathrm{MPa}$. The exposure times were varying from five to 20 minutes. The micrographs were obtained by irradiating the specimens with a beam of electrons of energy $5 \mathrm{keV}$. The irradiation live-time was 120 seconds. The surface area 


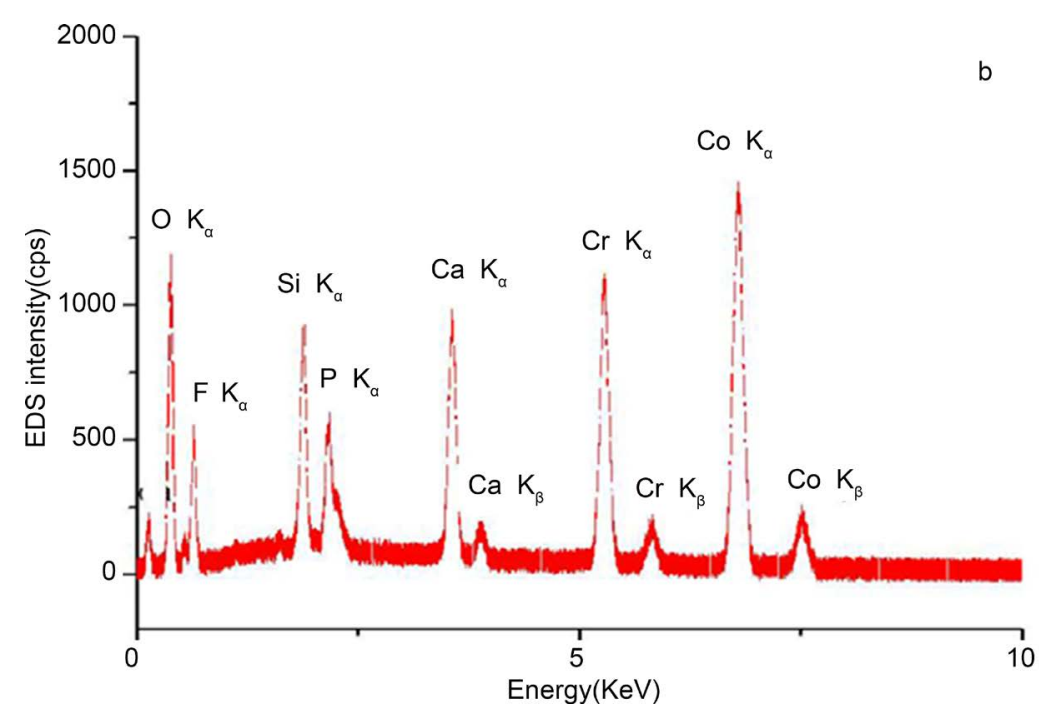

Figure 8. The energy dispersive $\mathrm{X}$-rays (EDAX) analysis of fluorapatite nanopowder Co-Cr-Mo alloy coatings by Pulsed Laser Deposition. In the specimen preparation the laser energy was $130 \mathrm{~mJ}$ and the pressure was maintained at 7 $\times 10^{-9} \mathrm{MPa}$

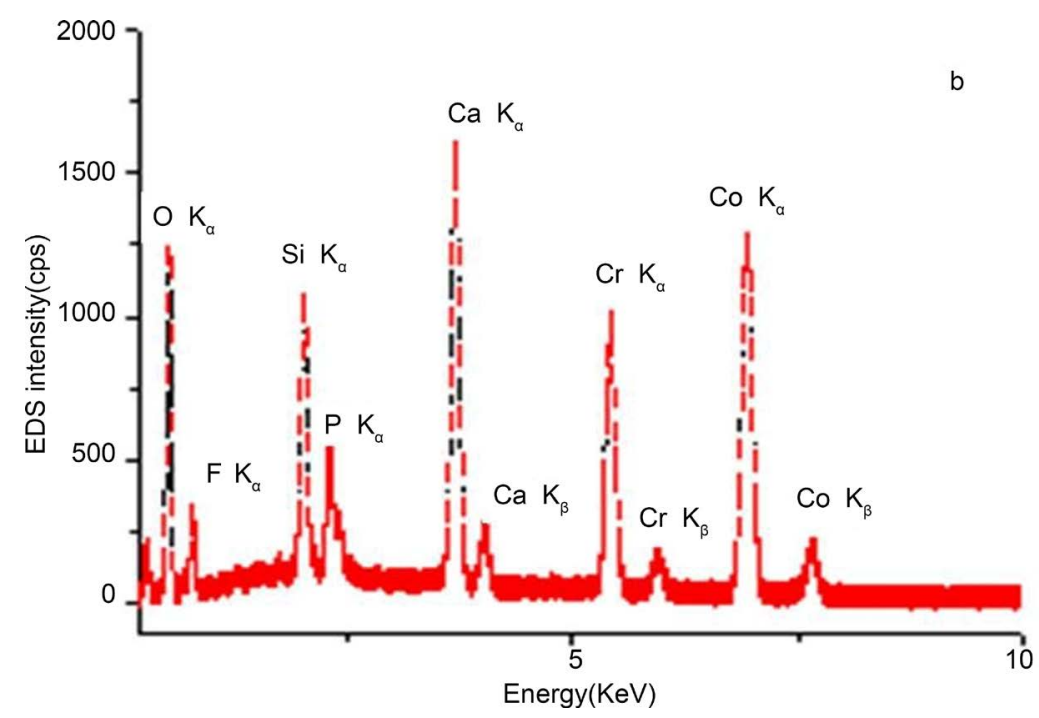

Figure 9. The energy dispersive X-rays (EDAX) analysis of fluorapatite nanopowder Co-Cr-Mo alloy coatings by Pulsed Laser Deposition.

scanned was approximately $10 \mu \mathrm{m} \times 10 \mu \mathrm{m}$ and where necessary, a larger area was selected.

The exposure time in the specimen preparation was five minutes. The EDAX analysis was obtained by irradiating the specimen with a beam of electrons of energy $20 \mathrm{keV}$. The irradiation live-time was 120 seconds. The data were measured with a silicon ultra-thin window (SUTW).

In the specimen preparation the laser energy was $130 \mathrm{~mJ}$ and the pressure was maintained at $7 \times 10^{-9} \mathrm{MPa}$. The exposure time in the specimen preparation was 10 minutes. The EDAX analysis was obtained by irradiating the specimen with a beam of electrons of energy $20 \mathrm{keV}$. The irradiation live-time was 120 seconds. 


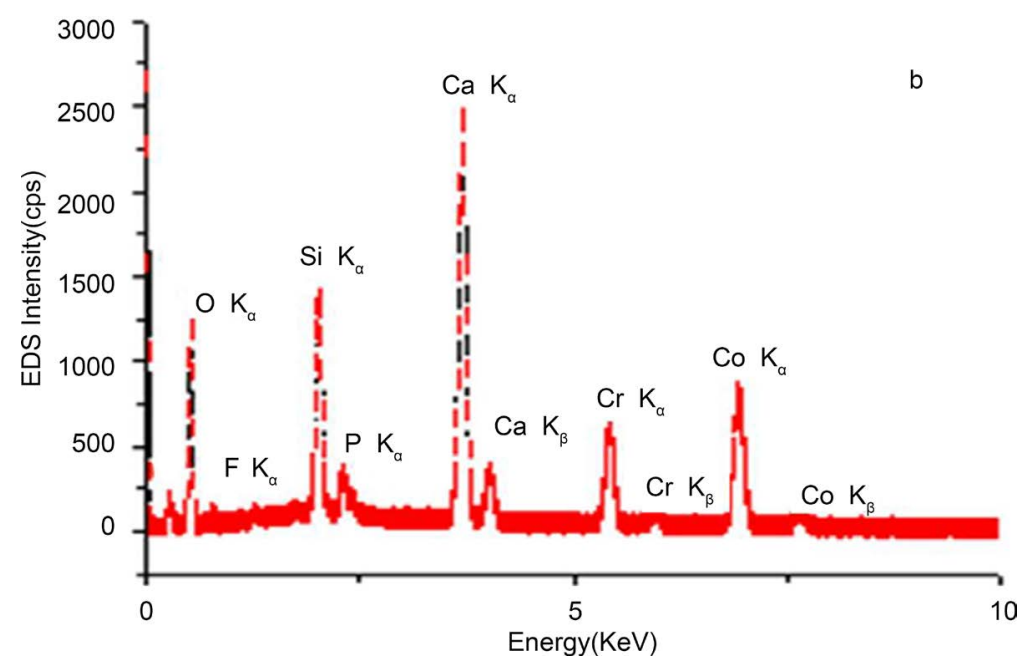

Figure 10. The energy dispersive X-rays (EDAX) analysis of fluorapatite nanopowder Co-Cr-Mo alloy coatings by Pulsed Laser Deposition. In the specimen preparation the laser energy was $130 \mathrm{~mJ}$ and the pressure was maintained at $7 \times 10^{-9} \mathrm{MPa}$.

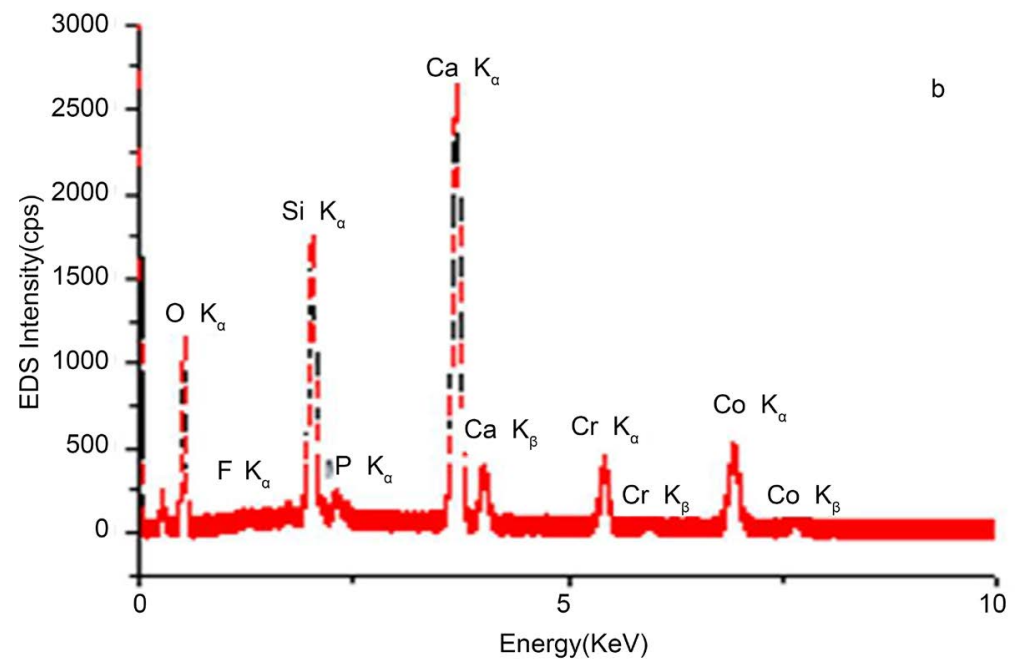

Figure 11. The energy dispersive X-rays (EDAX) analysis of fluorapatite nanopowder Co-Cr-Mo alloy coatings by Pulsed Laser Deposition. In the specimen preparation the laser energy was $170 \mathrm{~mJ}$ and the pressure was maintained at $7 \times 10^{-9} \mathrm{MPa}$.

The data were measured with a silicon ultra-thin window (SUTW).

The exposure time in the specimen preparation was 20 minutes. The EDAX analysis was obtained by irradiating the specimen with a beam of electrons of energy $20 \mathrm{keV}$. The irradiation live-time was 120 seconds. The data were measured with a silicon ultra-thin window (SUTW).

The exposure time in the specimen preparation was 10 minutes. The EDAX analysis was obtained by irradiating the specimen with a beam of electrons of energy $20 \mathrm{keV}$. The irradiation live-time was 120 seconds. The data were measured with a silicon ultra-thin window (SUTW).

In the specimen preparation the laser energy was $170 \mathrm{~mJ}$ and the pressure was 


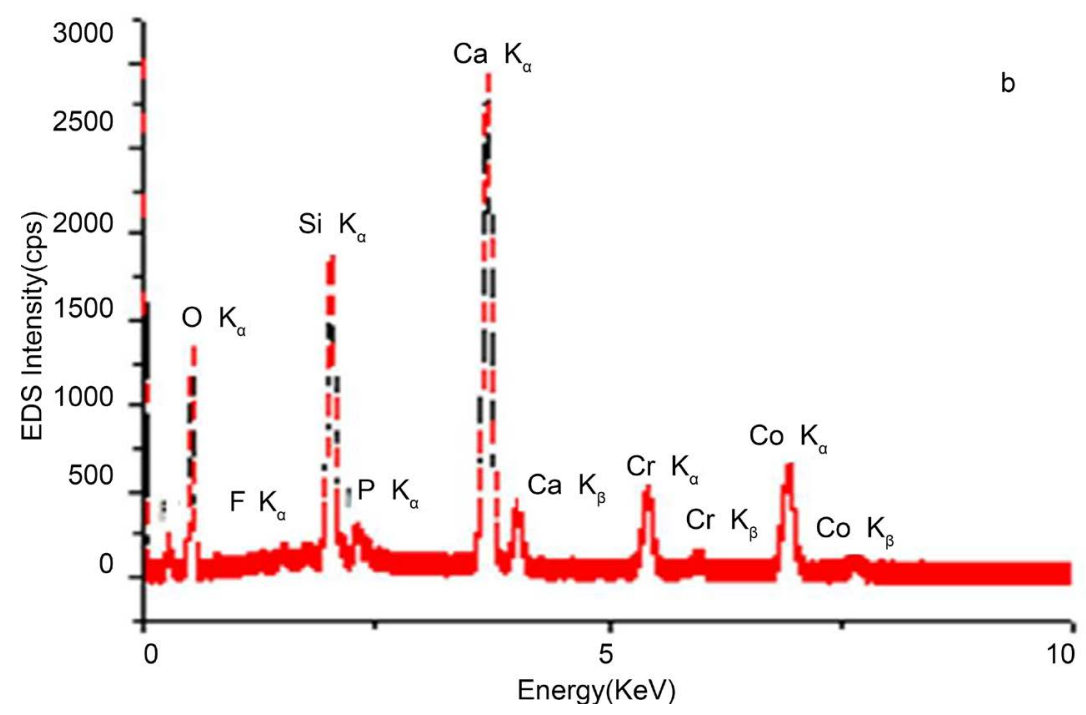

Figure 12. The energy dispersive X-rays (EDAX) analysis of fluorapatite nanopowder Co-Cr-Mo alloy coatings by Pulsed Laser Deposition.

maintained at $7 \times 10^{-9} \mathrm{MPa}$. The exposure time in the specimen preparation was 15 minutes. The EDAX analysis was obtained by irradiating the specimen with a beam of electrons of energy $20 \mathrm{keV}$. The irradiation live-time was 120 seconds. The data were measured with a silicon ultra-thin window (SUTW).

\subsection{Instrumental Analysis of the Specimens after Immersion into Simulated Body Fluid (SBF)}

\subsubsection{Microstructural Topology Analysis of Samples by SEM}

The electron micrographs of the microstructural topologies of the fluorapatite nanopowder Co-Cr-Mo alloy nanocomposite after exposed to simulated body fluid are shown in Figures 13-17. The laser energies were $130 \mathrm{~mJ}$ and $170 \mathrm{~mJ}$ and the pressure was maintained at $7 \times 10^{-9} \mathrm{MPa}$. The exposure times varied from five to 20 minutes. The micrographs were obtained after irradiating the specimens with a beam of electrons of energy $5 \mathrm{keV}$. The irradiation live-time was 120 seconds. The surface area scanned was approximately $10 \mu \mathrm{m} \times 10 \mu \mathrm{m}$, and a larger area was selected where necessary. The magnification was $9000 \times$ and the working distance was kept at $4.2 \pm 0.2 \mathrm{~mm}$.

A significant degree of agglomeration occurred in the specimen prepared at $130 \mathrm{~mJ}$ energy and an exposure time period of five minutes. Void (only the Co-Cr-Mo alloy surface visible) areas were observed. This is indicative of the depletion of the deposited layer. A similar phenomenon occurred in the instance of the specimen prepared at the same energy but for an exposure time of $10 \mathrm{mi}$ nutes. The extent of depletion of the deposited layer is however not as extensive as in the case of the five minute exposure specimen. As the layer thickness increased, the extent of depletion of the deposited layer decreased.

The laser energy was $130 \mathrm{~mJ}$ and the pressure was maintained at $7 \times 10^{-9} \mathrm{MPa}$. The exposure time was five minutes. The micrograph was obtained by irradiating the specimen with a beam of electrons of energy $5 \mathrm{keV}$. The irradiation 


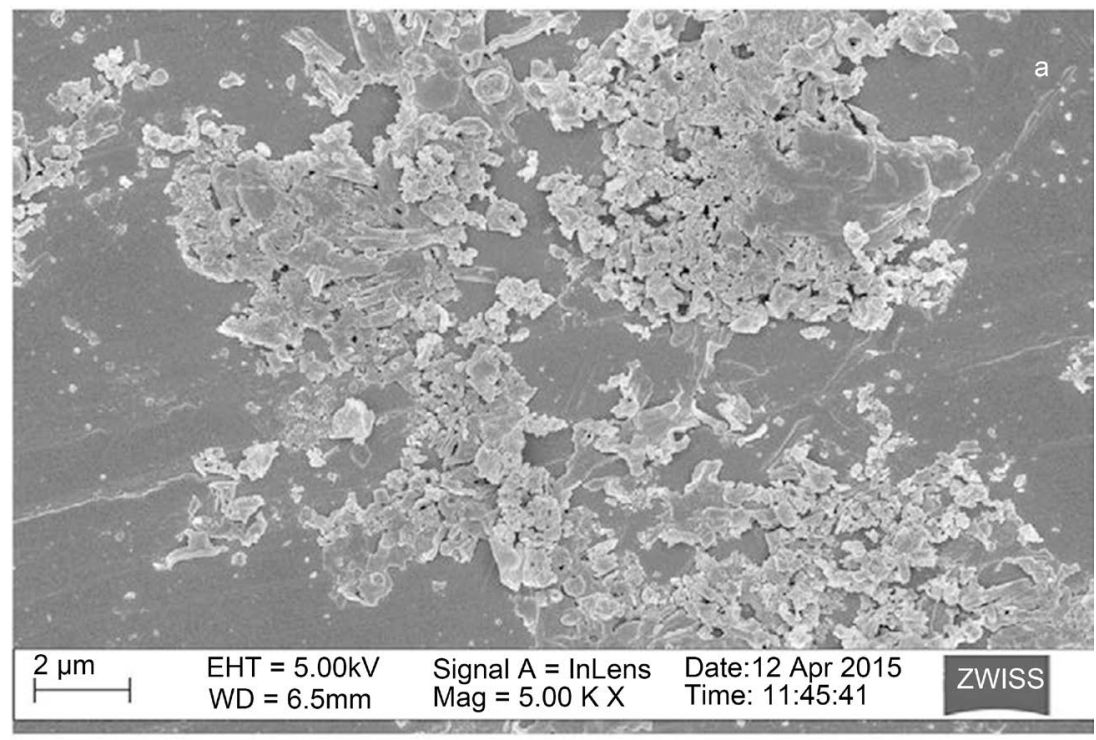

Figure 13. Electron micrograph of the microstructural topology of fluorapatite nanopowder Co-Cr-Mo alloy coatings.

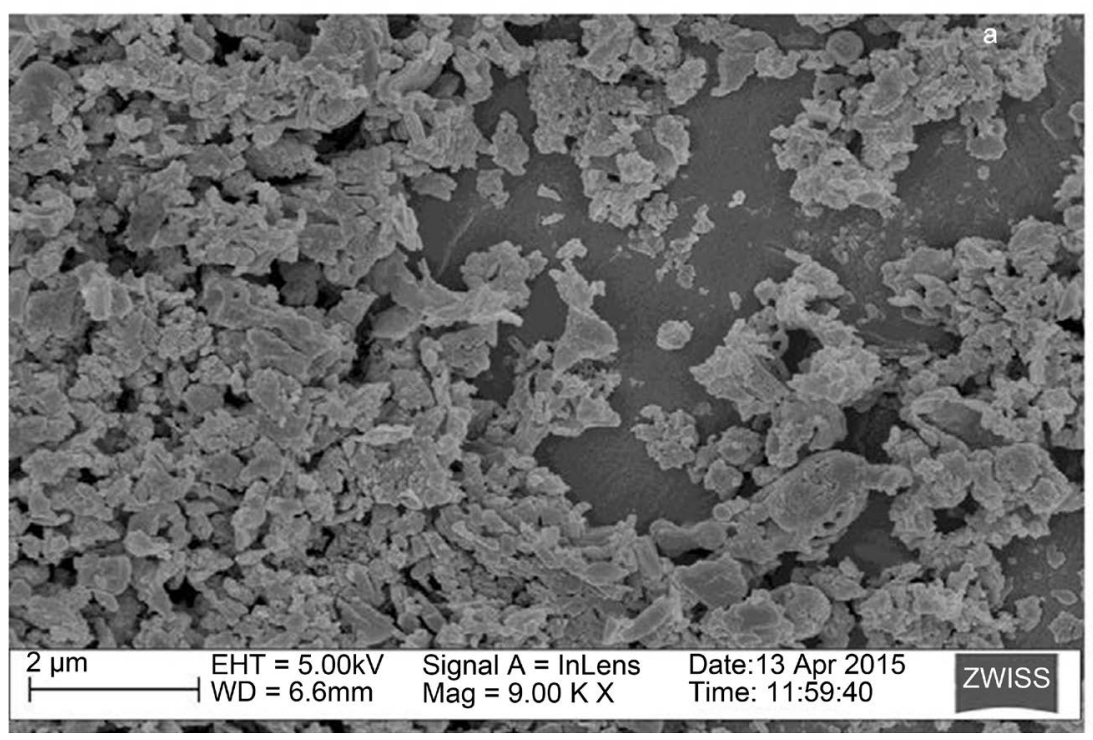

Figure 14. Electron micrograph of the microstructural topology of fluorapatite nanopowder-Co-Cr-Mo alloy coatings by pulsed laser deposition.

live-time was 120 seconds and the working distance was kept maintained at $4.2 \pm$ $0.2 \mathrm{~mm}$. The surface area scanned was $10 \mu \mathrm{m} \times 10 \mu \mathrm{m}$ and where necessary, a larger area was selected.

The laser energy was $130 \mathrm{~mJ}$ and the pressure was maintained at $7 \times 10^{-9} \mathrm{MPa}$. The exposure time was 10 minutes. The micrograph was obtained by irradiating the specimen with a beam of electrons of energy $5 \mathrm{keV}$. The irradiation live-time was 120 seconds and the working distance was kept maintained at $4.2 \pm 0.2 \mathrm{~mm}$. The surface area scanned was $10 \mu \mathrm{m} \times 10 \mu \mathrm{m}$ and where necessary, a larger area was selected.

The laser energy was $130 \mathrm{~mJ}$ and the pressure was maintained at $7 \times 10^{-9} \mathrm{MPa}$. 


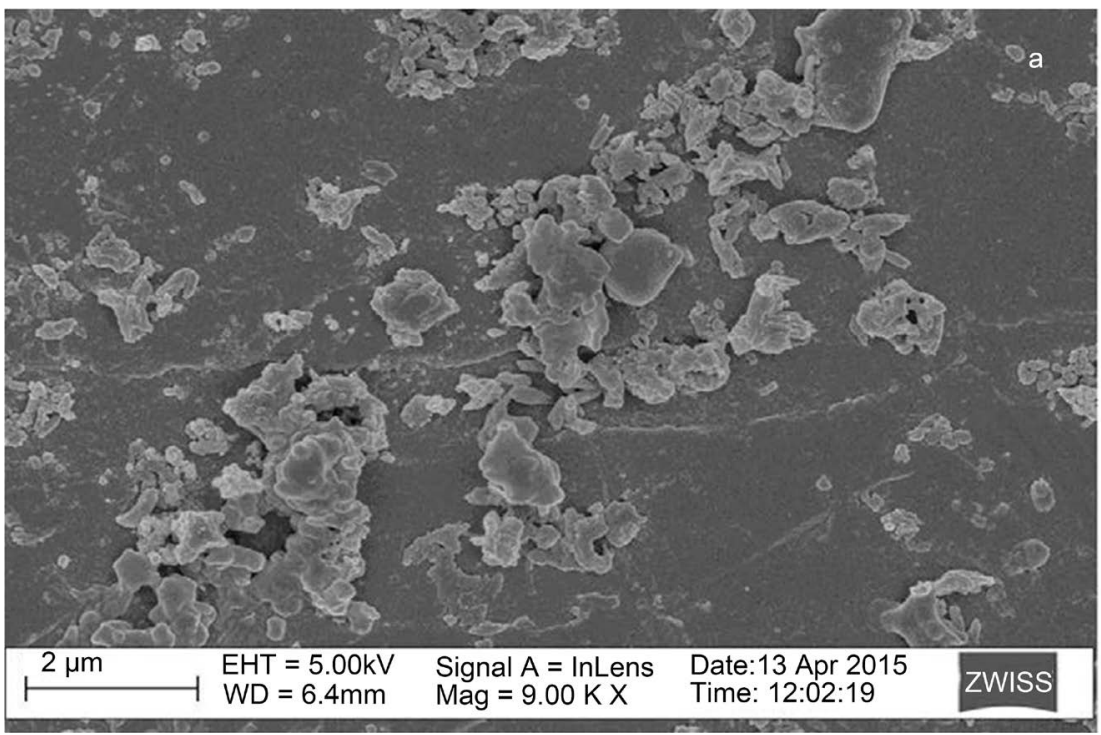

Figure 15. Electron micrograph of the microstructural topology of fluorapatite nanopowder-Co-Cr-Mo alloy coatings by pulsed laser deposition.

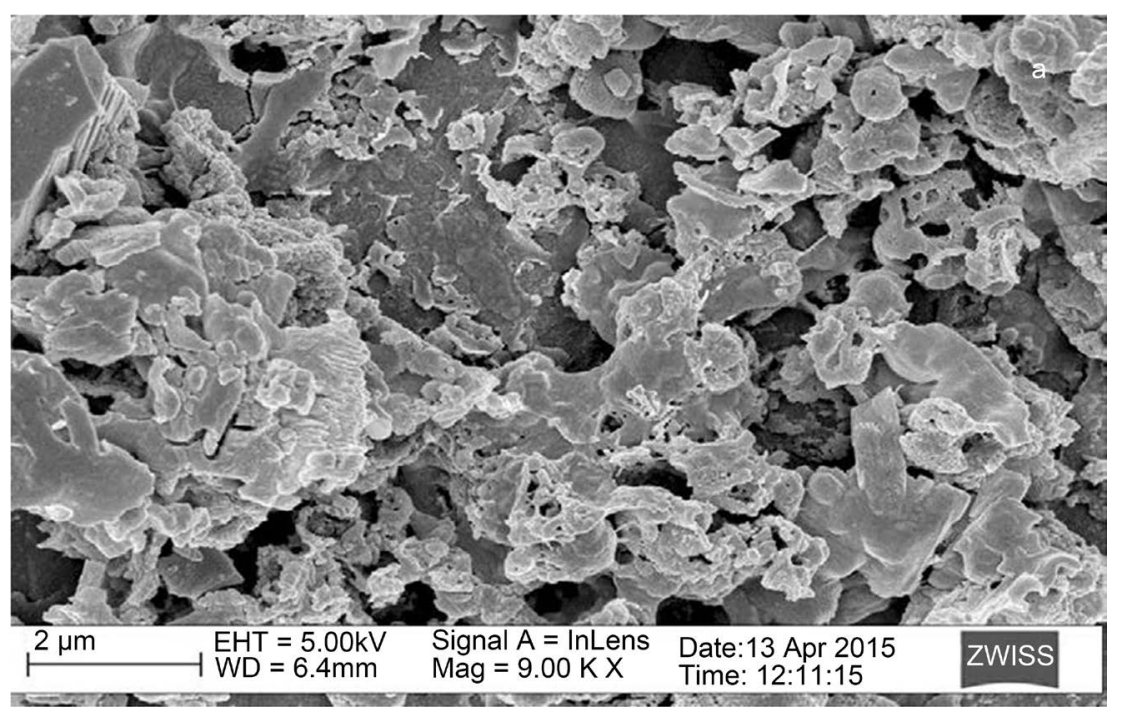

Figure 16. Electron micrograph of the microstructural topology of fluorapatite nanopowder-Co-Cr-Mo alloy coatings by pulsed laser deposition.

The exposure time was 20 minutes. The micrograph was obtained by irradiating the specimen with a beam of electrons of energy $5 \mathrm{keV}$. The irradiation live-time was 120 seconds and the working distance was kept maintained at $4.2 \pm 0.2 \mathrm{~mm}$. The surface area scanned was $10 \mu \mathrm{m} \times 10 \mu \mathrm{m}$ and where necessary, a larger area was selected.

The laser energy was $170 \mathrm{~mJ}$ and the pressure was maintained at $7 \times 10^{-9} \mathrm{MPa}$. The exposure time was 10 minutes. The micrograph was obtained by irradiating the specimen with a beam of electrons of energy $5 \mathrm{keV}$. The irradiation live-time was 120 seconds and the working distance was kept maintained at $4.2 \pm 0.2 \mathrm{~mm}$. The surface area scanned was $10 \mu \mathrm{m} \times 10 \mu \mathrm{m}$ and where necessary, a larger area was selected. 


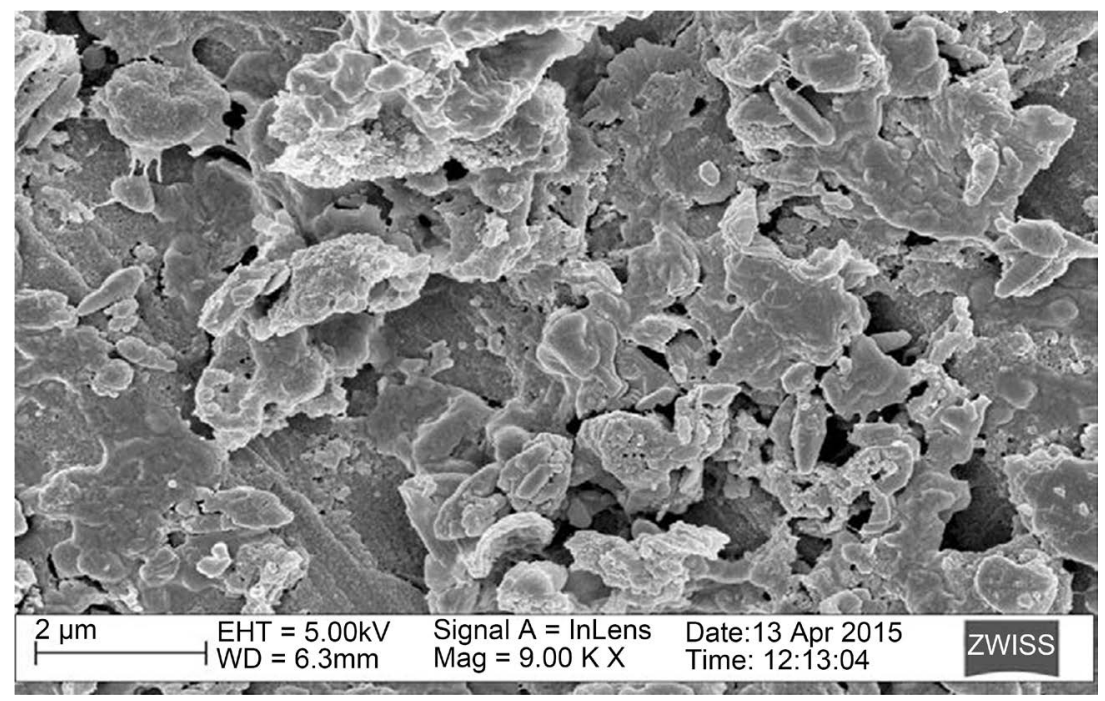

Figure 17. Electron micrograph of the microstructural topology of fluorapatite nanopowder-Co-Cr-Mo alloy coatings by pulsed laser deposition.

The laser energy was $170 \mathrm{~mJ}$ and the pressure was maintained at $7 \times 10^{-9} \mathrm{MPa}$. The exposure time was 15 minutes. The micrograph was obtained by irradiating the specimen with a beam of electrons of energy $5 \mathrm{keV}$. The irradiation live-time was 120 seconds and the working distance was kept maintained at $4.2 \pm 0.2 \mathrm{~mm}$. The surface area scanned was $10 \mu \mathrm{m} \times 10 \mu \mathrm{m}$ and where necessary, a larger area was selected.

\subsubsection{Energy Dispersive Analysis of X-Rays (EDAX) Analysis}

The energy dispersive analysis of X-rays (EDAX) analysis (shown in Figures 18-22) of the samples were fluorapatite nanopowder was coated onto the Co-Cr-Mo alloy are shown in Figures 3-7. The laser energy was set at $130 \mathrm{~mJ}$ and $170 \mathrm{~mJ}$ and the pressure was maintained at $7 \times 10^{-9} \mathrm{MPa}$. The exposure times varied from five to 20 minutes. The micrographs were obtained by irradiating the specimens with a beam of electrons of energy $5 \mathrm{keV}$. The irradiation live-time was 120 seconds. The surface area scanned was approximately $10 \mu \mathrm{m} \times$ $10 \mu \mathrm{m}$.

In the specimen preparation the laser energy was $130 \mathrm{~mJ}$ and the pressure was maintained at $7 \times 10^{-9} \mathrm{MPa}$. The exposure time in the specimen preparation was five minutes. The EDAX analysis was obtained by irradiating the specimen with a beam of electrons of energy $20 \mathrm{keV}$. The irradiation live-time was 120 seconds. The data were measured with a silicon ultra-thin window (SUTW).

In the specimen preparation the laser energy was $130 \mathrm{~mJ}$ and the pressure was maintained at $7 \times 10^{-9} \mathrm{MPa}$. The exposure time in the specimen preparation was 10 minutes. The EDAX analysis was obtained by irradiating the specimen with a beam of electrons of energy $20 \mathrm{keV}$. The irradiation live-time was 120 seconds. The data were measured with a silicon ultra-thin window (SUTW).

In the specimen preparation the laser energy was $130 \mathrm{~mJ}$ and the pressure was maintained at $7 \times 10^{-9} \mathrm{MPa}$. The exposure time in the specimen preparation was 20 minutes. The EDAX analysis was obtained by irradiating the specimen with a 


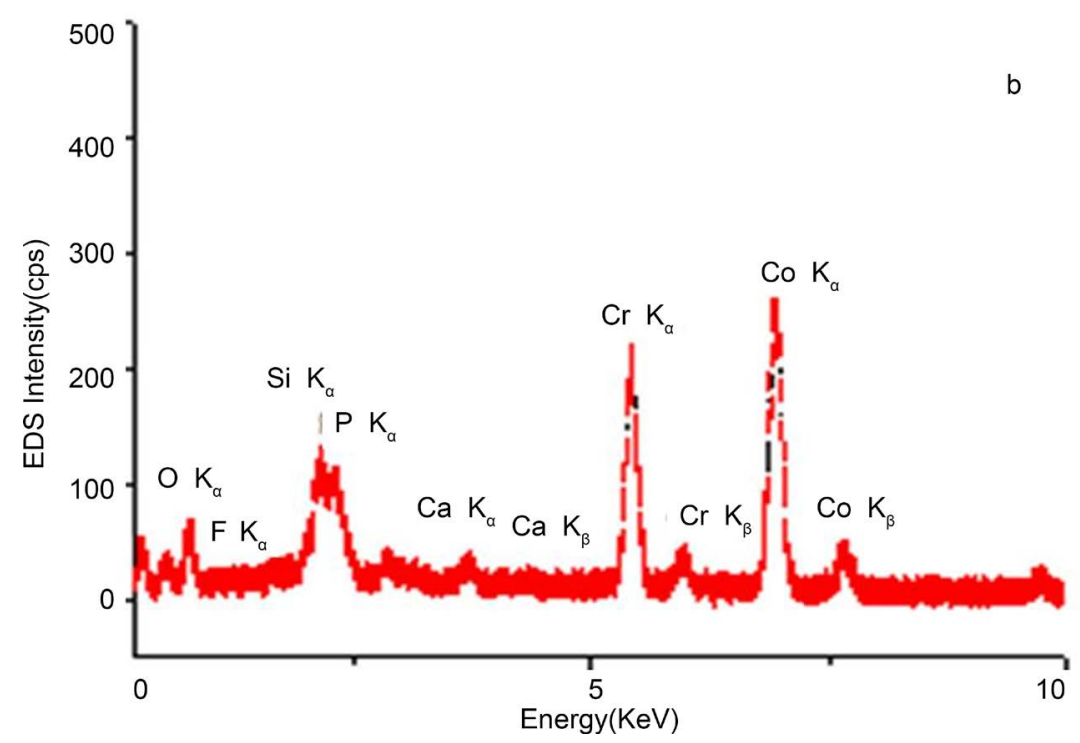

Figure 18. The energy dispersive analysis of X-rays (EDAX) analysis of the specimen in which fluorapatite nanopowder was coated onto Co-Cr-Mo alloy by pulsed laser deposition.

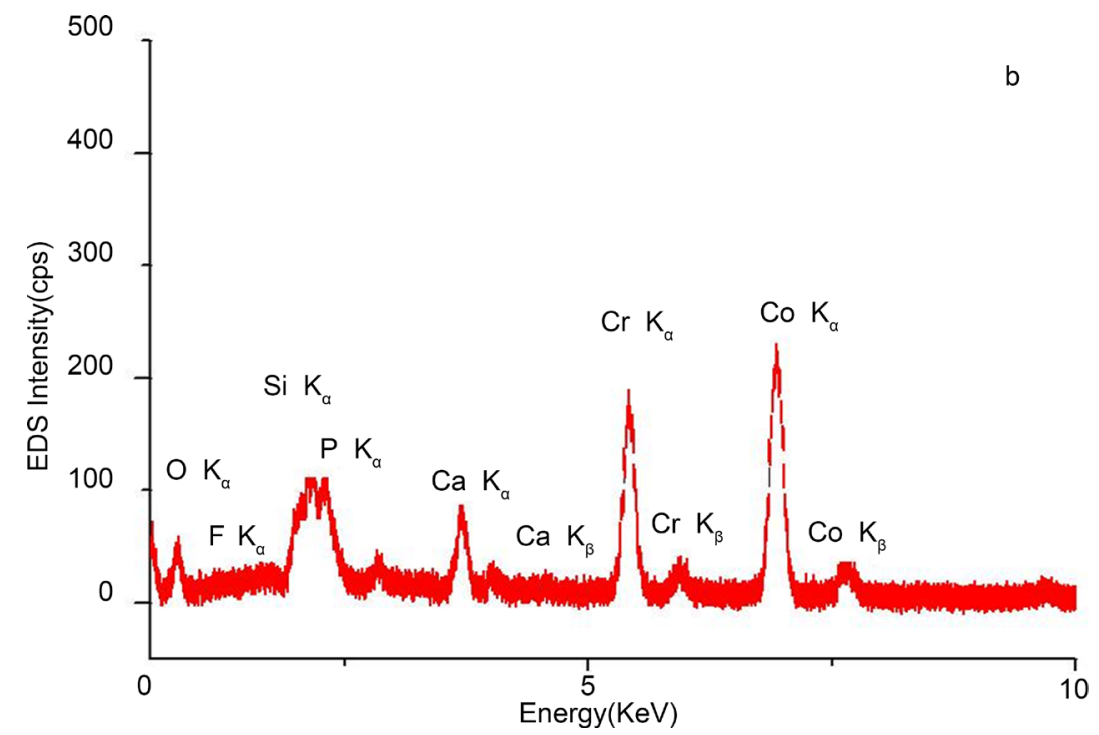

Figure 19. The energy dispersive analysis of X-rays (EDAX) analysis of the specimen in which fluorapatite nanopowder was coated onto Co-Cr-Mo alloy by pulsed laser deposition.

beam of electrons of energy $20 \mathrm{keV}$. The irradiation live-time was 120 seconds. The data were measured with a silicon ultra-thin window (SUTW).

In the specimen preparation the laser energy was $170 \mathrm{~mJ}$ and the pressure was maintained at $7 \times 10^{-9} \mathrm{MPa}$. The exposure time in the specimen preparation was 10 minutes. The EDAX analysis was obtained by irradiating the specimen with a beam of electrons of energy $20 \mathrm{keV}$. The irradiation live-time was 120 seconds. The data were measured with a silicon ultra-thin window (SUTW).

In the specimen preparation the laser energy was $170 \mathrm{~mJ}$ and the pressure was maintained at $7 \times 10^{-9} \mathrm{MPa}$. The exposure time in the specimen preparation was 


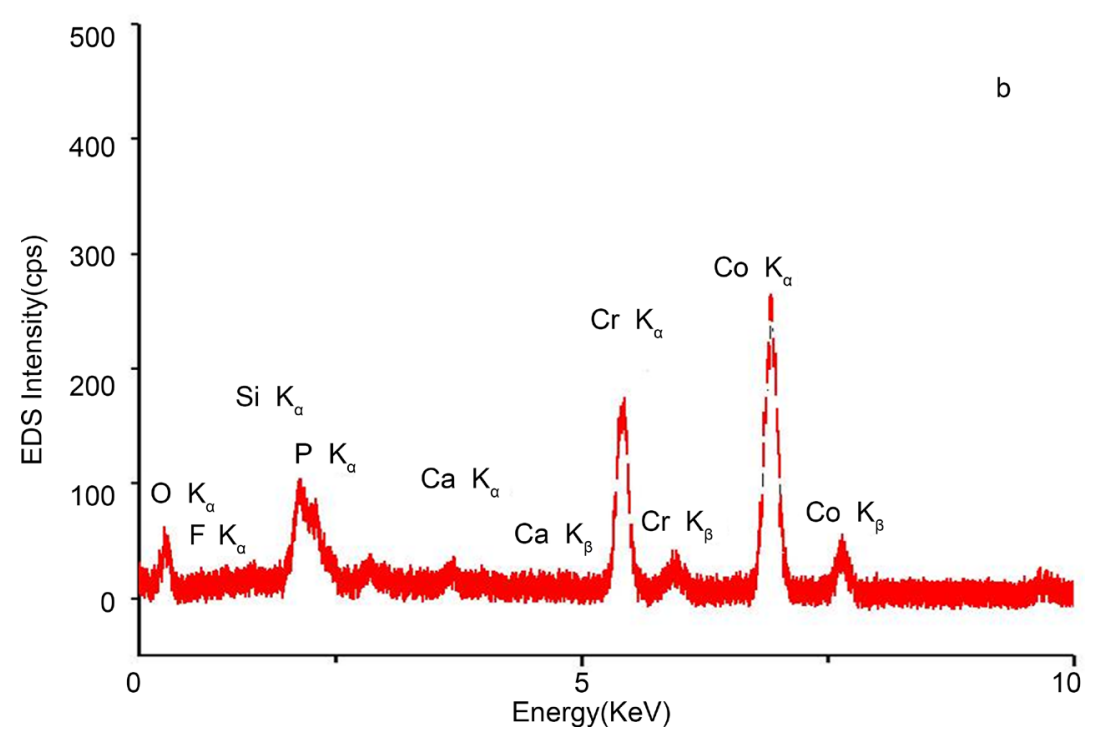

Figure 20. The energy dispersive analysis of X-rays (EDAX) analysis of the specimen in which fluorapatite nanopowder was coated onto Co-Cr-Mo alloy by pulsed laser deposition.

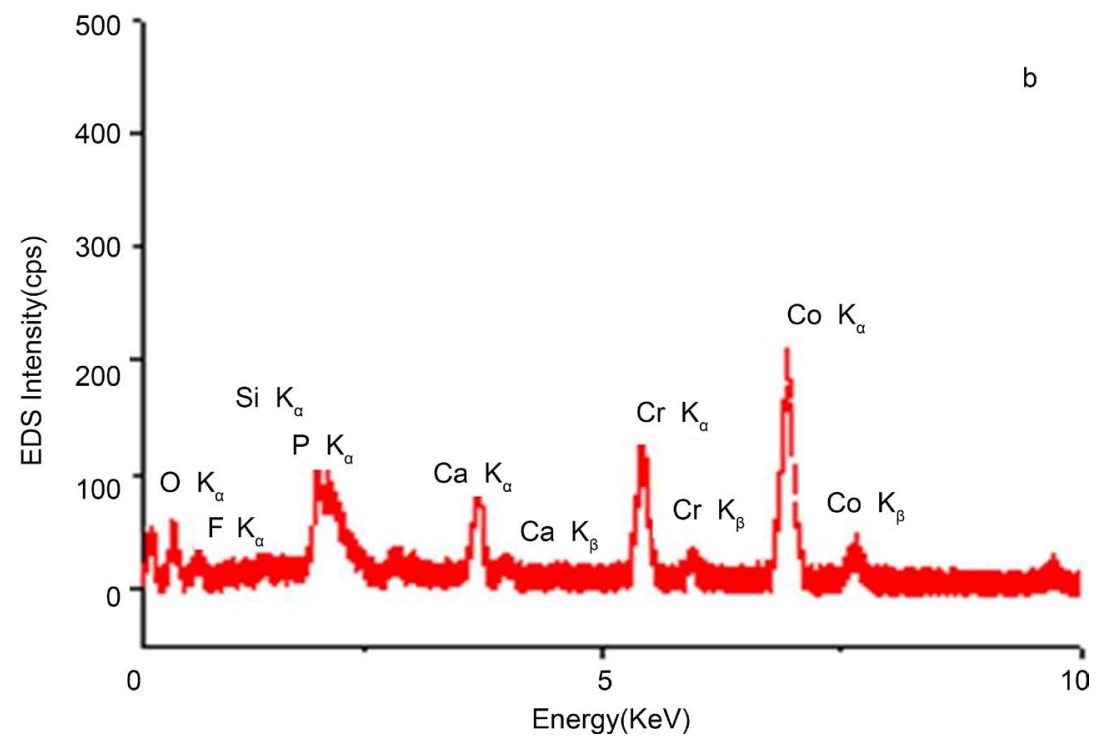

Figure 21. The energy dispersive analysis of X-rays (EDAX) analysis of the specimen in which fluorapatite nanopowder was coated onto Co-Cr-Mo alloy by pulsed laser deposition.

15 minutes. The EDAX analysis was obtained by irradiating the specimen with a beam of electrons of energy $20 \mathrm{keV}$. The irradiation live-time was 120 seconds. The data were measured with a silicon ultra-thin window (SUTW).

\section{Conclusion}

In this study, the FA/Co-Cr-Mo nanocomposite was successfully synthesized using pulsed laser deposition technique. The bioactivity assay of the nanocomposite after 14 days test on SBF, showed no corrosion but intact stability and biocompatibility. These were confirmed using various characterizing techniques 


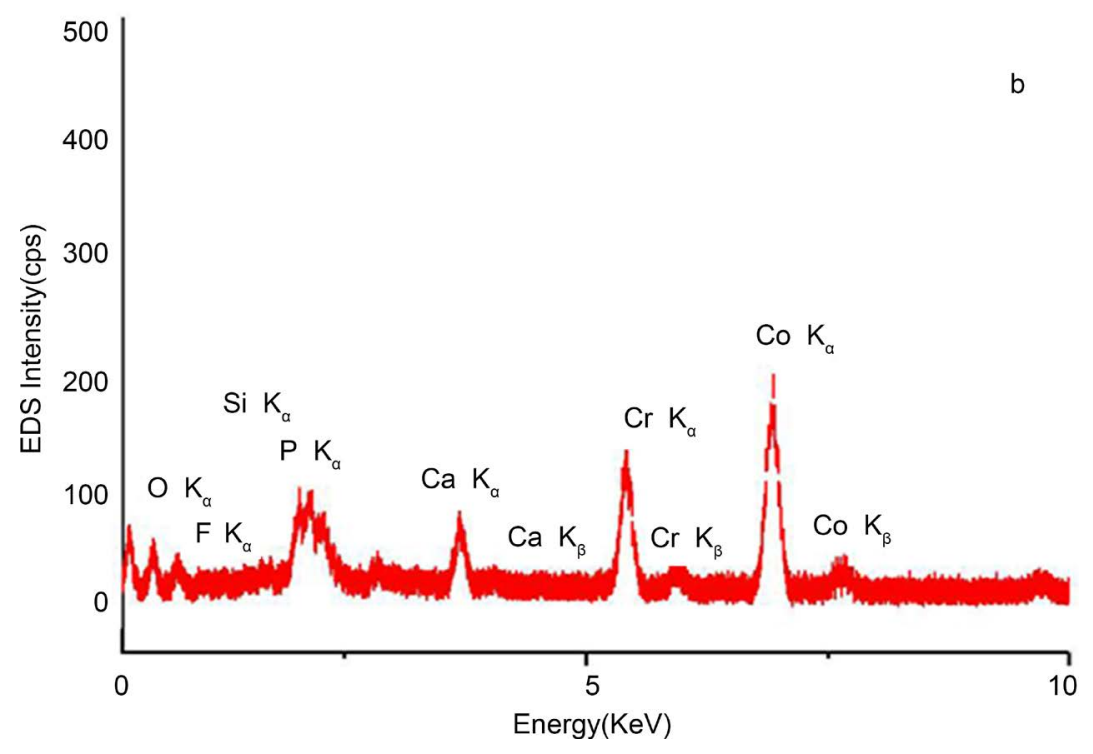

Figure 22. The energy dispersive analysis of X-rays (EDAX) analysis of the specimen in which fluorapatite nanopowder was coated onto Co-Cr-Mo alloy by pulsed laser deposition.

such as XRD, SEM and EDAX. The EDAX results indicated that the decrease in the degree of depletion was also connected with the increase in the comparative concentration ratio of the concentration of $\mathrm{Ca}$ to that of $\mathrm{Cr}$. Considering the results obtained from this study, for the samples prepared at $130 \mathrm{~mJ}$ and exposed for five minutes, the concentration ratio of $\mathrm{Ca}$ to $\mathrm{Cr}$ was found to be 0.91 before immersed in the test solution (SBF), of which after the test solution (SBF) the concentration increased to greater than 200. As the time of exposure increased to 10 minutes the concentration ratio of $\mathrm{Ca}$ to $\mathrm{Cr}$ also increased to 5.0 before test solution, of which increased to 0.5 and 3 respectively after test solution (SBF). From these results, it can be deduced that the increase in exposure time as well as the energy of the laser beam, which should be greater or equivalent to $170 \mathrm{~mJ}$ must be taken into consideration during laser deposition.

\section{Acknowledgements}

The research programme was generously supported by grants from Libyan Government and Libyan Embassy funding agency, the National Research Foundation of South Africa (NRF, MM 2015-TANZ), the French Center National pour la Recherche Scientifique (MM2015 CNRS), iThemba LABS, The UNESCOUNISA African Chair in Nanoscience and Nanotechnology (MM2015U2ACN2), the Organization of Women in Science for the Developing World (OWSDW, MM2015OWSDW) and the Abdus Salam ICTP via the Nanoscience African network (NANOAFNET, MM2015ICTP) as well as the African Laser Center (ALC, MM2015ALC) to whom we are grateful.

\section{References}

[1] Galo, R., Rocha, L.A., Faria, C.A., Silveira, R.R., Ribeiro, R.F. and Chiarello de Mat- 
tos, M. (2014) Influence of the Casting Processing Route on the Corrosion Behavior of Dental Alloys. Materials Science and Engineering C, 45, 519-523. https://doi.org/10.1016/j.msec.2014.10.006

[2] Nuoh, T., Andre Mars, J., Thovhogi, N., Gihwala, D., Baleg, A.A. and Maaza, M. (2015) Influence of Temperature and $\mathrm{pH}$ on Corrosion Resistance of $\mathrm{Ni}-\mathrm{Cr}$ and $\mathrm{Co}-$ Cr Dental Alloys on Oral Environment. Journal of Dental and Oral Health, 1, 5.

[3] Hussain, S. (2009) Investigation of Structural and Optical Properties of Nanoceystalline Zn. M.Sc. Thesis, Available Online.

[4] Postek, M.T.P., Howard, K.S., Johnson, A.T. and McMiche, K.L. (2001) Scanning Electron Microscopy. Ladd Research Industries, Williston.

[5] Wang, X.Y., Rice, D.M., Lee, Y.S. and Downer, M.C. (1994) Time-Resolved Electron-Temperature Measurement in a Highly Excited Gold Target Using Femtosecond Thermionic Emission. Journal of Physical Review, 50, 8016. https://doi.org/10.1103/PhysRevB.50.8016

[6] Supady, J. (2010) Types of Tooth Filling Used in Dental Treatment in 19th Century. Journal of Stomatology, 63, 273-281.

[7] Reimann, Ł. and Dobrzański, L.A. (2011) Microstructure and Hardness of Base Cobalt Alloys Used in Dentistry Engineering. In: Pacyna, J., Ed., Works of XXXIX Materials Engineering School. Monograph, Krakov-Krynica, Vol. 49, 198-202.

[8] Powers, J.M. and Sakaguchi, R.L. (2006) Craig's Restorative Dental Materials. 12th Edition, Mosby, Missouri, 386-393.

[9] Ohtsuki, C., Aoki, Y., Kokubo, T., Bando, Y., Neo, M. and Nakamura, T. (1995) Transmission Electron Microscopic Observation of Glass-Ceramic A-W and Apatite Layer Formed on Its Surface in a Simulated Body Fluid. Journal of the Ceramic Society of Japan, 103, 449-454. https://doi.org/10.2109/jcersj.103.449

[10] Goodhew, P.J., Humpreys, T. and Branland, R. (2001) Electron Microscopy \& Analysis. 3rd Edition, Taylor \& Francis Group, New York.

[11] Yamanaka, K., Mori, M. and Chiba, A. (2015) Surface Characterisation of Ni-Free Co-Cr-W-Based Dental Alloys Exposed to High Temperatures and the Effects of Adding Silicon. Corrosion Science, 94, 411-419. https://doi.org/10.1016/j.corsci.2015.02.030

[12] Kokubo, T. and Nan-Cryst, J. (1990) Surface Chemistry of Bioactive Glass-Ceramics. Journal of Nao-Crystalline Solids, 120, 138-151. https://doi.org/10.1016/0022-3093(90)90199-V

[13] Montero-Ocampo, C., Talavela, M. and Lopez, H. (1999) Effect of Alloy Preheating on the Mechanical Properties of As-Cast Co-Cr-Mo-C Alloys. Metallurgical and Material, 30, 611-620. https://doi.org/10.1007/s11661-999-0052-6

[14] Braic, M., Balaceanu, M., Vladescu, A., Kiss, A., Braic, V., Epurescu, G., Moldovan, A., Birjega, R. and Dinescu, M. (2007) Preparation and Characterization of Titanium Oxynitride Thin Films. Applied Surface Science, 253, 8210-8214. https://doi.org/10.1016/j.apsusc.2007.02.179

[15] Montero-Ocampo, C., Talavela, M. and Lopez, H. (1999) Effect of Alloy Preheating on the Mechanical Properties of As-Cast Co-Cr-Mo-C Alloys. Metallurgical and Materials Transactions A, 30, 611-620. https://doi.org/10.1007/s11661-999-0052-6 
Submit or recommend next manuscript to SCIRP and we will provide best service for you:

Accepting pre-submission inquiries through Email, Facebook, LinkedIn, Twitter, etc. A wide selection of journals (inclusive of 9 subjects, more than 200 journals)

Providing 24-hour high-quality service

User-friendly online submission system

Fair and swift peer-review system

Efficient typesetting and proofreading procedure

Display of the result of downloads and visits, as well as the number of cited articles Maximum dissemination of your research work

Submit your manuscript at: http://papersubmission.scirp.org/

Or contact msa@scirp.org 